\title{
Problems and Countermeasures of Bike-Sharing System in China Based on the theory of Public Goods
}

\section{Danlin Ruan* Liping Pan}

Hefei No.6 High School, Hefei, Anhui, 230000, China

\begin{tabular}{ll}
\hline ARTICLE INFO & ABSTRACT \\
$\begin{array}{l}\text { Article history } \\
\text { Received: } 24 \text { September } 2020\end{array}$ & $\begin{array}{l}\text { Under the new normal of China's economic development, bike-sharing, } \\
\text { a new product of the "Internet +" era, opens the door to a novel lifestyle } \\
\text { for the society, and is in the stage of rapid development. Nevertheless, } \\
\text { with the explosive growth of the number of bicycles, some new problems } \\
\text { Accepted: } 9 \text { October } 2020\end{array}$ \\
$\begin{array}{l}\text { gradually come out, such as disorderly parking, serious damage and waste } \\
\text { of resources, which in turn restrict its further development. Based on the } \\
\text { theory of public goods, this article studies the quasi-public goods attri- }\end{array}$ \\
$\begin{array}{l}\text { Keywords: } \\
\text { butes and problems of bike-sharing, as well as provides feasible measures } \\
\text { fike-sharing }\end{array}$ & $\begin{array}{l}\text { for its long-term development, so as to realize the co-governance and } \\
\text { sharing among enterprises, consumers and government. }\end{array}$ \\
Theory of public goods &
\end{tabular}

\section{Introduction}

$\mathrm{W}$ ith the urbanization and expansion of cities, transportation system has become an important part of the city. However, the development of roads dominated by private cars has brought a series of problems, such as traffic congestion, heat island effect, and environmental pollution and so on. The concept of "Low-Carbon" and "Green Transportation" has become increasingly prominent.

From the perspective of space occupation and carbon emission, "Green Transportation" mainly includes walking, bikes, buses and rail transit. Among them, buses and rail transit have long played significant roles in urban public transport system. Bicycles, however, were privately owned and used over a long period of time. The earliest bike-sharing system appeared in 1965 in the Netherlands, while the domestic public bicycle system appeared before and after the 2008 Olympic Games in some big cities, such as Beijing, Hangzhou, Wuhan, etc. After 2014, with the rapid spread of Internet technology, dockless shared bikes led by Mobike and ofo began to replace the public bike system dominated by the government, and became a preferred method to solve the "last kilometer" of urban travel. But at the same time, bike-sharing has increasingly brought about prominent problems. The future development of bike-sharing thus lies mainly in the solution of those problems, including parking, recovery and maintenance, related legal issues, etc.

\section{The Theory of Public Goods}

\subsection{Definition and Mathematical Expression}

The development of the theory of public goods can be traced back to the classical school, represented by David Hume's analysis of "grassland drainage" and Adam Smith's theory on the three functions of the government.

*Corresponding Author:

Danlin Ruan,

Hefei No. 6 High School, Hefei, Anhui, 230000, China;

E-mail:779172960@qq.com. 
In the 1950s, Paul A. Samuelson completed a classical definition of public goods, until then, the theory of modern public goods was formally established. Starting from the definition of public goods, he and his later economists, such as Richard Abel Musgrave, carried out a series of studies on the optimal supply of public goods and its operating mechanism, which drove the theory of public goods to grow in a more detailed way.

According to Samuelson, public goods, which he called "collective consumption goods" in his landmark paper "The Pure Theory of Public Expenditure" in 1954, are non-rival and non-excludable, that is, one individual's consumption of such good does not lead to the reduction of availability to others, and anyone cannot be excluded from use or could benefit from without paying for it. There are three characteristics of public goods which are significantly different from private products or services: Indivisibility of utility; Non - competition of consumption; Non - excludability of benefits. On the contrary, private products are rival, excludable, rejectable, traded in the free market with opportunity cost. The products between the two are called quasi-public goods.

The difference between public goods and private goods is expressed in mathematical form as follows:

(1) Public goods: $\mathrm{G}=\mathrm{Gi}$

The formula shows that for any consumer $i$, the quantity of public goods Xi consumed is equal to the quantity $\mathrm{X}$ of public goods, indicating that public goods are indivisible and that all people consume the same amount of public goods.

(2) Private products: $\mathrm{G}=\sum \mathrm{Gi}$

The total amount of a private product $\mathrm{X}$ is the sum of the number Xi owned or consumed by $\mathrm{N}$ consumers. That is to say, a private product owned or consumed by a certain consumer is only a part of the total amount of private products, which means that private products are distributable among people.

\subsection{Characteristics}

\subsubsection{Non-Excludability of Benefits}

Non - excludability means that it is technically impossible or meaningless to prevent others from consuming because of high cost, that is, people can benefit from without paying for it. Because of this, anyone who consumes public goods does not exclude other people's consumption, there will inevitably bring about a "Free-Riding" phenomenon where public goods benefit free-riders, those who have not paid for it.

\subsubsection{The Indivisibility of Utility}

Private goods can be divided into many units that can be bought and consumed by different people, whereas public goods are available collectively, shared by all members of the society and are inseparable. The indivisibility of utility is actually the extension of the non - excludability of benefits.

\subsubsection{Non - Competition of Consumption}

Marginal production cost is zero: in the existing level of public goods supply, new consumers entering do not result in the increase of supply costs. (e.g., the lighthouse)

Marginal congestion cost is zero: anyone's consumption of public goods will not affect the quantity and quality of other people enjoying the same public product at the same time, which means that individuals cannot adjust the quantity and quality of their consumption.

Whether the marginal congestion cost is zero is an important standard to divide the types of public goods.

\subsection{Classification}

Public goods are generally divided into pure public goods and quasi-public goods (i.e. mixed goods).

Pure public goods are consumed by the whole society. Strictly speaking, they are non-rival and non-excludable. In addition, they are also indivisible. Their consumption is shared by many consumers on the premise of maintaining their integrity.

Quasi-public goods are located between public goods and private goods, which do not have the property of pure public goods or private products, but to some extent, they have the nature of these two products more or less at the same time. On the whole, quasi-public goods cannot be non-rival and non-excludable in the meantime, otherwise they will become pure public goods. Similarly, quasi-public goods cannot be rival and excludable at the same time, or they will become private products.

\section{Shared Bikes}

\subsection{Definition}

Robin Chase, co-founder and former CEO of Zipcarthe first car-sharing company in the world, expounded main points of "sharing economy" in her bookPeers Inc: How People and Platforms are Inventing the Collaborative Economy and Reinventing Capitalism: Using idle resources to achieve utility; Internet platform promoted by science and technology; Influential people are the main participants. In summary, the sharing economy has the following characteristics:

1)Tripartite model: the supply-side, the demand-side and the platform-side are independent of each other

2)The supplier and the demander meet the interactive 
demand through the platform

3)The platform-side does not own resources, and only promotes transactions

4)The utility of unilateral access to platform depends on the size of the other side

According to the above conditions, traditional companies like Airbnb, Uber and DiDi all have typical business models of sharing economy. However, the existing bicycle rental enterprises based on Mobile Internet technology, in the name of "sharing", just use the convenience of scientific advancement to innovate the traditional bicycle operation mode, which actually does not belong to "sharing economy". The so-called "shared bikes "are exactly "Internet rental bikes".

From the perspective of public goods, the shared-bike is a kind of quasi-public good, quite different from public rental bicycles funded by government with the mission of public welfare operation. First of all, the shared-bike is completely controlled by market forces, whereas the supplier of public rental bicycles is the government. Secondly, the user experience of shared-bikes is better than that of public rental bicycles, mainly due to the convenience of dock-free and self-service. Compared with traditional bicycles that need to be stationed in the dock, operation places of sharing-bike are far more than traditional and public rental bicycle system. But uncontrolled parking of shared-bikes has also occupied some public space.

\subsection{Characteristics}

As a quasi-public product, bike-sharing has the following characteristics.

\subsubsection{Non-competition}

From the perspective of Aggregate Supply-Aggregate Demand Model, the actual operation volume of bike-sharing is very large, already reaching the saturation of market demand. Additionally, there is no congestion cost for shared bikes. Under the current sufficient input, one more new consumer using will not affect the quantity and quality of shared bicycles enjoyed by other consumers, thus in theory, there will not induce additional production cost.

\subsubsection{Excludability}

At the technical level, bike-sharing excludes people who are not willing to pay for their use. Charging on time also ensures that a certain shared-bike brings benefits to specific users who pay for their use and are in the use period.

In the way of use, the excludability is reflected in indispensable elements of employing, such as the mobile phone, network, app, network payment and suitable target bikes.
In law, bike-sharing, as a non-motor vehicle, is also excludable. According to Article 72 of $<$ Regulation on the Implementation of the Road Traffic Safety Law of the People's Republic of China>, cycling must be at least 12 years old.

\subsubsection{Profitability}

Different from the public bicycles funded by the government, shared bikes are provided by enterprises for the purpose of making profits. The excludability is the guarantee of the profitability. Its profit model is considered to guarantee the bottom with rent and provide profit potential with deposit. However, in the late period of capital harvest, its profitability and capital sustainability are widely questioned. Moreover, advertising placement is also a means of profit.

\subsubsection{Externality}

Externality refers to the positive or negative external influence on the welfare of others.

The positive externalities of shared bikes are mainly reflected in two aspects-traffic and environment. Bike-sharing, as a means of transportation to solve the "last mile", makes the public transportation system more perfect and systematic. Furthermore, as a substitute for motor vehicles, it is conducive to reduce exhaust emissions and improve the environment. The negative externalities of bike sharing are manifested in the non-standard parking and public space occupation caused by the overflow of bikes, which affect the normal function of public facilities and induced legal problems as well as potential security risks in road operation.

\subsection{Problems}

Although bike-sharing has solved problems of market failure and government failure in short distance travel, it has also given rise to new problems in management, such as excessive production, lack of parking planning in management links, etc. This paper analyzes existing issues of shared bikes from the angle of quasi-public goods.

\subsubsection{Insufficiency of Non-competition}

The lack of non-competition is reflected in unbalanced regional supply and untimely bike-scheduling. In the initial stage, in order to increase market share, bike-sharing companies choosed to put bicycles in areas with large traffic volume. Under such a strategic deployment, the per capita share of shared-bike in the regions with large flow of people far exceeds those in the remote and sparsely populated areas, resulting in the imbalance of regional supply. 
In addition, since the main purpose of bicycle travel in the city is commuting, the number and location of bikes are almost the same as the tidal changes of traffic, so it is necessary to carry out dispatching management. However, in reality, companies often only focus on the number of bicycles, losing sight of scheduling.

\subsubsection{Insufficiency of Excludability}

This is the main reason for many bike-sharing management problems.

The phenomenon of free-riding is manifested by many people riding the same bike, breaking the car lock or even adding a lock on shared-bike for private use, etc. This phenomenon not only brings huge losses to bike-sharing companies, but also damages consumer welfare, and even causes a waste of social resources.

\subsubsection{The Unsustainability of Profitability}

The market of bike-sharing is a game of capital, where the key point of capital investment is the huge deposit instead of the rent. In fact, due to the single source of income and poor anti-risk capability, the profitability of bike-sharing is very weak. Especially because of the extremely high damage rate, low utilization and recovery rate, the cost of production and maintenance is a huge burden. Most bike-sharing companies are insolvent and have serious book deficits. Even with capital support, the business situation will not be optimistic in the short term.

\subsubsection{The Social Cost Caused by Externality Is Huge}

Bike-sharing is a kind of special behavior that consumes both private goods (bicycle itself) and public resources (road space). The particularity of using public resources will inevitably produces a negative externalities after the market scale reaches a certain limit, which will bring cost to the society. At present, bike-sharing has greatly reduced the short-term cost of travel, and has been enlarged into a "market" with the participation of capital. Nevertheless, due to the crowding effect, just in terms of the space and way of parking, bike-sharing has caused various inconveniences to the environment, society and economy, for example, the congestion cost caused by the confusion in parking, deposit and information security cost.

\section{Countermeasures}

\subsection{Enterprises: Strengthen the Sense of Respon- sibility}

Bike-sharing companies have made some contributions in the supply of public transport, but they also produces some problems in the process of production and management, which have brought about negative social effects. In order to get rapid development and customer recognition, these companies must shoulder social responsibility. In reality, the supply of shared-bikes exceeds the demand that consumers can consume and the degree that the society can accept. This excessive supply to occupy the market is overcapacity and waste of resources. Therefore, the industry should adjust production, digest excess capacity, improve the recovery rate of waste bikes, and reduce resource loss. Moreover, it is also necessary to create a diversified profit model to resist multi-risks. In terms of information security, consumers' privacy should be protected to avoid the leakage of personal information. As for bicycle management, the regional input olume ought to be reasonably planed with a peak control, maintenance and recycling of bikes should be timely carried out to improve the utilization rate as well as reduce the occupation of public space.

\subsection{Citizens: Cultivate Social Consciousness}

Consumer behavior affects the development of bike-sharing. Improving moral literacy and civic awareness will help to reduce the operating cost and solve many problems in the use of bike-sharing. The "dockless" characteristic of should not be shown as disorderly parking, and consumers should not affect public order for their own convenience. The unqualified children-riding problem is more the responsibility of guardians and schools. Abiding by traffic rules is the basic guarantee of travel safety. If consumers can correct their bad behavior, problems such as high damage rate, low utilization rate and public space occupation, etc., will be gradually solved, which in turn gives companies the possibility of making profits and the incentive to provide better service experience in the long run, forming a virtuous circle.

\subsection{Government: Give Full Play to Government Functions}

First, the government should act as a regulator. It is undeniable that "bike-sharing" is a new trend that is worth encouraging in the social and economic development under the background of the current Internet technology revolution. However, as a part of the market economy, we cannot ignore the possibility of various market failures. Even at the level of the industry itself, is there unfair competition and monopoly? Is it harmful to the interests of consumers? Is there any economic and financial risk? And whether it will overdevelop and cause some external 
effects? All these call on the government to give regular market supervision. Of course, market regulation is not to restrict the development of "bike-sharing", on the contrary, it is just to promote a better and healthier development. For the moment, there seems to be a lack of regulatory measures for shared-bikes, not good for its long-term development.

Second, the government should act as the supplier of public goods. As far as all kinds of shared transportation modes are concerned, they still belong to the category of urban transportation in essence. Based on the utilization of urban public land resources, whether it is buses, taxis, or shared-bikes, they must have more or less some attributes of public goods. Focusing on the healthy and orderly development of the city, what the government should ensure is to provide necessary public transport infrastructure and public goods. Of course, the government can not only provide public goods through its own direct supply, but also through the way of third-party purchase. Yet, no matter what mode of supply, the government cannot ignore its responsibility in creating and providing transportation services. In this regard, the government should consider how to effectively participate shared-bikes production in terms of public goods supply. Only when they are included in the public goods for urban transportation, can it truly demonstrate the responsibility of the government as a public goods's supplier, which is also the largest support and encouragement for bike-sharing industry.

Third, the government should also play the role of "Administrator". In the supply of urban public transportation, apart from the economic relationship between supply and demand, there are also social relationships in the sense of governance, which are reflected in how to integrate social factors such as communities and individuals into the construction process of urban transport, and how to eliminate all kinds of negative externalities to the greatest extent through the "co-governance" relationship among the three parties - the government, market and society, instead of relying solely on administrative or market forces. For example, in the case of disorderly parking of shared bikes, there are not only the reasons for parking space planning, but also factors of bicycle scale and pricing. Besides, it cannot be denied that the lack of traffic civilization is also a cause. As a result, so as to solve this problem, in addition to efforts of the government and companies, how to cultivate and promote a civilized travel habit in the whole society is the key to solve this problem in the long run.
During this process, relevant departments of the government should be good at "govern" related problems at the root through top-level design, rather than merely "solving" temporarily at the technical and economic levels.

\section{Conclusion}

In general, the development of bike-sharing has become a real market today. Since it is a market, the government should treat it according to the objective law of the market. Only in this way can the government's role as a market watchman and judge rather, than a protagonist, be truly highlighted.

\section{References}

[1] Paul A. Samuelson. The Pure Theory of Public Expenditure $[\mathrm{J}]$.the review of economics and statistics, 1954: P36.

[2] David Hume. A Treatise of Human Nature(Volume 2) [M]. The Commercial Press, 1983: P578-579.

[3] Wu Muxuan, Cheng Nan, Li Ling. The commonweal and operability of bicycle sharing from the perspective of rent and deposit $[\mathrm{J}]$. price theory and practice, 2017 (05).

[4] Ge Wenjing. Construction of shared bicycle value network model and Discussion on profit model -Taking mobike and OFO shared bicycle as an example [J]. China business theory, 2017 (15).

[5] Duan Liren, maolizeng. Analysis and Discussion on urban traffic right $[\mathrm{J}]$. integrated transportation, 2014 (03).

[6] Tan yuan. Research and prevention of the "bottom line competition" of sharing bikes [J]. price theory and practice, 2017 (03).

[7] Yu Guolei. Analysis of the problems and Countermeasures in the operation and management of "sharing bicycle" [J]. knowledge economy, 2017 (09).

[8] Guo Jianming. Economic thinking on sharing bikes [J]. reform and opening up, 2017 (06).

[9] Pan Zhen, Li Demin. On the diversified supply of quasi public goods in China [J]. Journal of Changchun University of Technology (SOCIAL SCIENCE EDITION), 2010 (04).

[10] Han Jianmin, Zhang Jing. Exploring the development of shared bikes from the perspective of quasi public product theory $[\mathrm{J}]$.china collective economy, issue 12, 2019 (April): 59-60. 